\title{
Coordinated Recovery Strategy for Multi-infeed HVDC Systems Based on MIESCR
}

\author{
Li Xiaobin ${ }^{1 *}$, Hu Shihao ${ }^{2}$ and Huang Haoyu ${ }^{3}$ \\ ${ }^{1,3}$ State Grid Jiujiang Electric Power Supply Company, Jiujiang, China \\ ${ }^{2}$ State Grid Jiujiang Chaisang District Power Supply Company, Jiujiang, China
}

\begin{abstract}
A coordinated recovery strategy, based on MIESCR, is proposed for the converters Excessive dynamic reactive power demand and the low speed of power transmission recovery in multi-infeed HVDC system in this paper. Firstly, the article deduces the consistency of two type definition of MIESCR, and uses the respective advantages of the definition to improve the physical meaning of MIESCR; and then it elaborates the role of MIESCR played in in MIDC system voltage and power-angle stability Third, this pages put forward MIESCR as the fundamental to distinguish the strength of AC system, and use the size of MIESCR to arrange the recovery order of DC systems. Furthermore, the parameter of PI controller is used to realize the control of each DC system current. There is a great method to ensure coordinate control of PI controller. The last, a double infeed HVDC system simulation model, based on two actual DC system of China Southern Power Grid, is built on Electromagnetic transient simulation software of PSCAD/EMTDC to confirm the validity of this method proposed in this paper.
\end{abstract}

\section{Introduction}

Multi-infeed high voltage Direct Current (MIDC) system has been formed in domestic power grid. The MIDC system not only improves the transmission capacity and the flexibility of the control mode, but also increases the complexity of the system structure, resulting in problems such as reactive voltage, power Angle stability and the interaction between $\mathrm{AC}$ and DC. Especially for the MIDC system at the receiving end, these problems are more intertwined, making the stability characteristics of the power grid system more complex.

Based on this, this paper proposes a method based on the Multi-infeed Effective Short Circuit Ratio (MIESCR) to realize the DC coordinated recovery of MIDC system. Firstly, the physical significance of MIESCR is analyzed and defined. Second, MIESCR as compared with the ac system attached to the back to dc relative strength index, adjustment and coordination of PI link parameters, avoid inverter recovery at the same time cause the inverter is too large to satisfy the demand of the reactive voltage and Angle stability, the influence of commutation failure, while eliminating the follow-up after failure of dc system orderly recovery. Finally, the simulation software of PSCAD/EMTDC electromagnetic transient is used to build a two-loop DC receiver doubly-fed system model of China Southern Power Grid, and the effectiveness of the proposed method is verified.

\section{MIDC system}

The research of MIDC system usually adopts multi-port equivalent simplification of AC part. As shown in Fig. 1, the N-fed HVDC transmission system model at the receiving end is equivalent to the $\mathrm{AC}$ system at the receiving end by using the Thevenin theorem. The AC system at the receiving end of the converter is simulated by a series combination of constant $\mathrm{AC}$ voltage source $E_{a c, i}$ and constant impedance $Z_{i, i}$. The capacitor, AC filter and other devices of the inverter station are regarded as the constant capacitance, whose capacity is $Q_{C i}$, and are paralleled on the converter bus at the receiving end. 


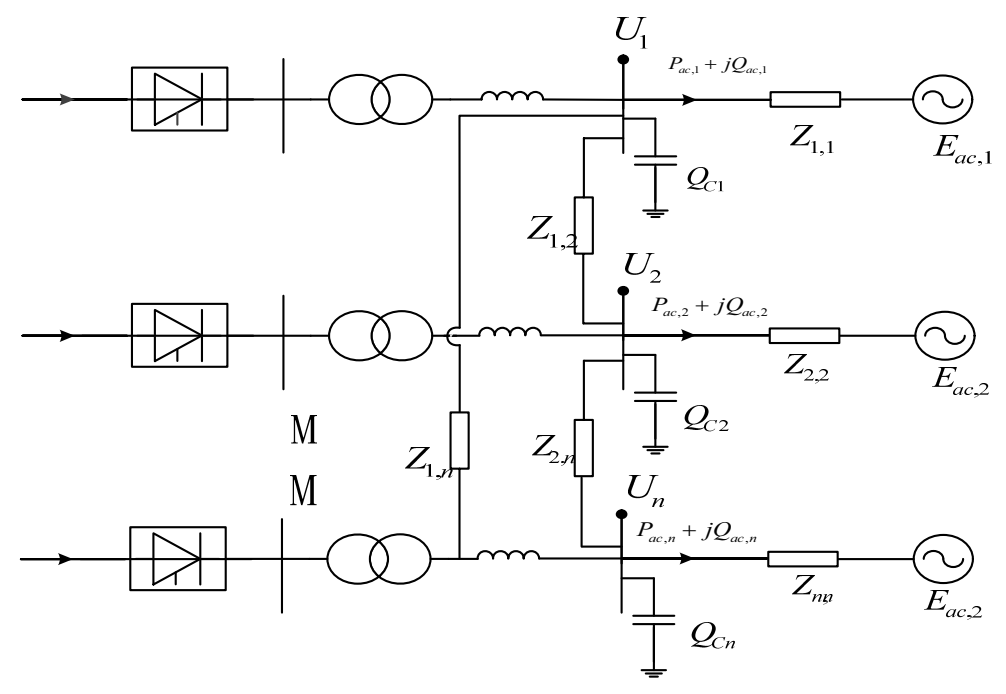

Fig.1. Multi-infeed DC equivalent system

The control mode of DC system is as follows, in steady state operation, the rectifier side and the inverter side are controlled by constant current and constant voltage respectively. When the fault occurs, the rectifier side is controlled by constant current, while the inverter side is controlled by constant current when the DC current is very small, but it is controlled by constant arc extinguishing Angle most of the time.

In this paper, PSCAD/EMTDC simulation modeling is adopted to study the characteristics of the DC system after failure based on the receiver doubly-fed AC/DC transmission system and discuss the orderly coordinated recovery strategy

\section{MIESCR Index}

\subsection{Physical Implications of MIESCR}

There are two definitions of MIESCR in MIDC systems, those defined by Paulo et al., and those defined by Cigre.

1) The derivation and final expression of the i-return DC MIESCR defined by Paulo et al are shown in Equations (1) (3).

$$
Y=\left[\begin{array}{cccc}
\sum_{j=1}^{n} \frac{1}{Z_{1, j}} & \frac{1}{Z_{1,2}} & \mathrm{~L} & \frac{1}{Z_{1, n}} \\
\frac{1}{Z_{2,1}} & \sum_{j=1}^{n} \frac{1}{Z_{2, j}} & \mathrm{~L} & \frac{1}{Z_{2, n}} \\
\mathrm{M} & \mathrm{M} & \mathrm{O} & \mathrm{M} \\
\frac{1}{Z_{n, 1}} & \frac{1}{Z_{n, 2}} & \mathrm{~L} & \sum_{j=1}^{n} \frac{1}{Z_{n, j}}
\end{array}\right]
$$

Where, $Z_{i, j}(i, j=1,2,3 \ldots \mathrm{n})$ is the equivalent coupling impedance between the $i$ and $j$ loops.

The node impedance matrix $Z$ is obtained by its inverse, as shown in Equation (2) .

$$
Z=Y^{-1}=\frac{A^{*}}{\operatorname{det}(Y)}
$$

Where, $A^{*}$ is the adjoint matrix and $\operatorname{det}(Y)$ is determinant of $\mathrm{Y}$, respectively.

$$
\operatorname{MIESCR}_{i, \text { Pau }}=\frac{S_{a c i}-Q_{C i}}{\sum_{j=1}^{n} \frac{\left|Z_{j}^{i}\right|}{\left|Z_{i}^{i}\right|} P_{d c j, e}}
$$

Where, $S_{a c i}$ is the short-circuit capacity of the connection of the $i$-return DC receiver; $Q_{C i}$ is the reactive power compensation capacity of the converter. $P_{d c j, e}$ is the $j$-return DC rated capacity, $Z_{j}^{i}$ is the node transfer mutual impedance of the element in row $j$ and column $I$ in matrix $Z$, and $Z_{i}^{i}$ is the node transfer self-impedance.

2) The MIESCR expression defined by CIGRE is shown in Equation (4).

$$
\operatorname{MIESCR}_{1, C I G}=\frac{S_{a c i}-Q_{C i}}{\sum_{j=1}^{n} M I I F_{i}^{j} P_{d c j, e}}
$$

Where, $M I I F_{i}^{j}$ is the multi-infeed interaction factor (MIIF) between the $i-j$ direct current, which can be defined by Equation (5).

$$
M I I F_{i}^{j}=\frac{\Delta U_{j}}{\Delta U_{i}}
$$

Where, $\Delta U_{i}$ is the voltage change of the bus caused by the small disturbance of the converter bus at the receiving end of the $i$-return $\mathrm{DC}$, and $\Delta U_{j}$ is the voltage change of the $j$-return DC converter bus caused by the $i$ return DC.

According to the two definitions, $M I I F_{i}^{j}$ is an experimental indicator, which can accurately reflect the interaction between DC subsystems, but it cannot predict the influence of grid structure change on this factor. $Z_{i}^{j}$ can reflect the change of power grid structure, but its physical meaning is not clear enough.

Therefore, the two definitions of MIESCR are consistent, indicating that the physical meaning of MIESCR in engineering and theory is clear. In this paper, 
the MIESCR analysis system defined by Paulo et al is reasonable in simulation verification.

\subsection{Application of MIESCR in Dynamic Characteristics of MIDC System}

The multi-feed effective short-circuit ratio reflects the structural strength of the MIDC system and the reactive voltage support capacity of the power grid to the converter bus, so the voltage stability of the MIDC system plays a certain role in the characterization. Moreover, the introduction of MIIF in MIESCR directly reflects the mutual influence and coupling relationship between multi-loop DC systems, and on this basis reflects the relative strength relationship between $\mathrm{AC}$ and DC systems.

In this paper, based on MIESCR index, the DC coordinated recovery research is carried out according to the strength of its voltage reactive power supporting capacity of DC system. In developing the recovery plan, the following factors are taken into account: the time when the dynamic reactive power of the converter consumption occurs, whether subsequent commutation failures occur, and the time required for the system to restore the active power to $90 \%$ of the rated value.

\section{Recovery based on MIESCR indicators}

Based on the clear physical significance of MIESCR and its application characteristics, the DC recovery sequence after disturbance can be realized by the staggered power upgrade strategy based on the size of MIESCR. The recovery strategy in this paper is divided into three steps:

1) Determine the DC control link that can affect the recovery sequence of the DC subsystem. Since the PI link does not work during the fault period, and the setting current is greatly affected by the parameters of the PI link during the recovery period, and the rectifying side is controlled by constant current before and after the fault, the current PI control link on the rectifying side can be adjusted to control the speed of DC recovery.

2) Restoring the DC subsystem successively according to the strength of the $\mathrm{AC}$ system at the receiving end of the DC system and the value of MIESCR. The strong system is used to support the system voltage during the recovery process to reduce the system voltage fluctuation. In order to avoid the lack of system reactive support due to the reactive power peak reached by the DC inverter during the process of recovery, the power recovery can be improved successively by using DC interleaving.

3) Coordinating the parameters of the PI control link of the fixed current at the rectifier side to control the orderly recovery of the DC subsystem. The PI link controller in the control layer of the control valve of the DC system is shown in Figure 2.

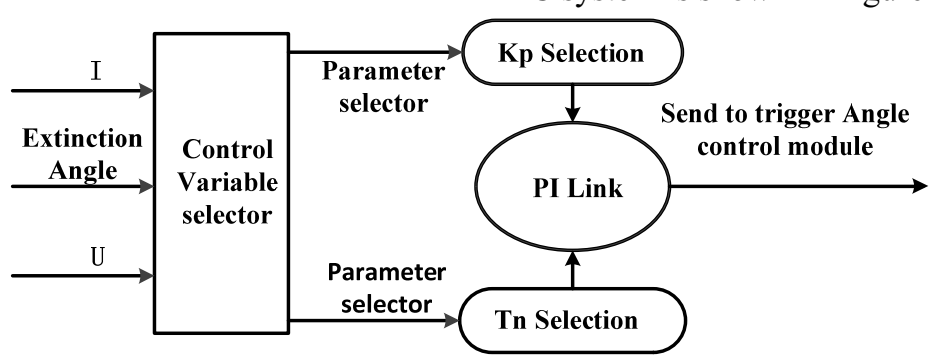

Fig.2 The schematic diagram of PI control link for DC system

The trigger Angle of the converter is adjusted through the parameters of the PI link to realize its control of the DC current. For the proportional gain $K_{p}$ and integral constant $T_{N}$ of PI link of the DC system, their values are closely related to the time when the peak of dynamic reactive power consumed by the converter appears. It is measured through experiments that the larger the $K_{p}$, the earlier the peak of reactive power appears, the earlier the DC recovery, and the larger the $T_{N}$ appears, the later the $T_{N}$ appears. Therefore, the orderly recovery of each DC can be realized by coordinating and tuning the $K_{p}$ and $T_{N}$ of each DC.

\section{The simulation verification}

Based on the PSCAD/EMTDC model of a two-loop DC of China Southern Power Grid, the receiver doubly-fed DC model is established. The detailed model was used for the two DC circuits. DCl was $\pm 800 \mathrm{kV}$ Chusui DC, rated power was $5000 \mathrm{MW}$, and the equivalent reactive compensation admittance was $B_{C l}=9.54 \times 10^{-6} \mathrm{~s}$. DC2 is $\pm 500 \mathrm{kV}$ Xing 'an DC, rated power is $3000 \mathrm{MW}$, equivalent reactive compensation admittance $B_{C 2}=6.20 \times 10^{-6} \mathrm{~s}$; AC system is represented by impedance plus constant voltage source. The whole network adopts standard unit system. The equivalent parameters of AC system grid are: voltage source $525 \mathrm{kV}, Z_{1,1}=30 \Omega$, $Z_{1,2}=38 \Omega, Z_{2,2}=16 \Omega$. A $100 \mathrm{~ms}$ three-phase short circuit fault is set on the converter bus at the receiving end. According to formula (1), it can be obtained $Z_{1}{ }^{l}=19.29 \Omega$, $Z_{1}^{2}=5.71 \Omega, Z_{2}^{2}=12.95 \Omega, Z_{1}^{2} / Z_{1}{ }^{l}=0.296, Z_{1}^{2} / Z_{2}^{2}=0.441$.

\subsection{Simulation Verifies the Consistency between Paulo et al. and CIGRE Defined MIESCR Index}

Set faults on DC1 and DC2 receiving converter buses, and simulate different severity of receiving converter buses by changing the value of ground impedance, as 
shown in Fig. 3. The dynamic voltage curve of threephase short circuit at DC2 receiving end is shown in Fig.

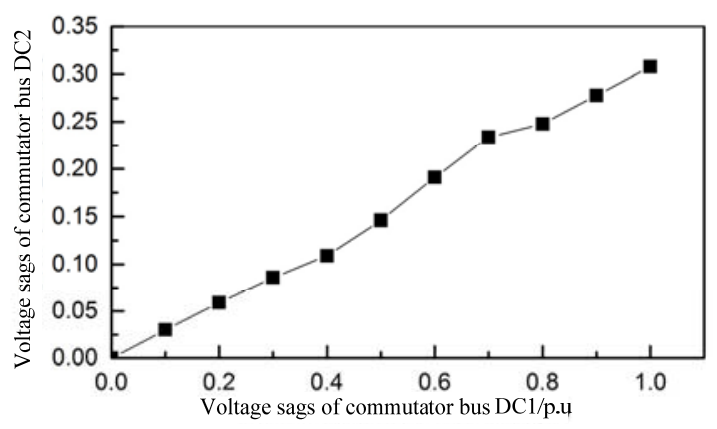

(a) The influence of DC1 voltage drop to DC2 4(a). The voltage of converter bus drops about $0.81 \mathrm{p} . \mathrm{u}$, and that of DC2 converter bus drops about 0.33p.u.

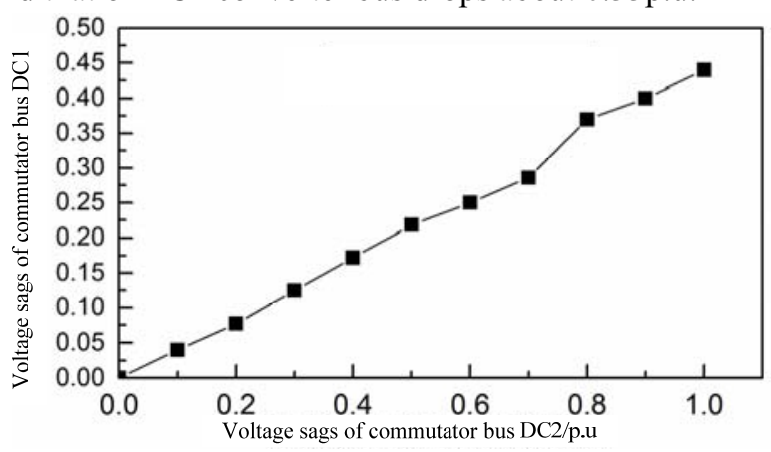

(b) The influence of DC2 voltage drop to DC1

Fig3. The influence between DCs voltage drop

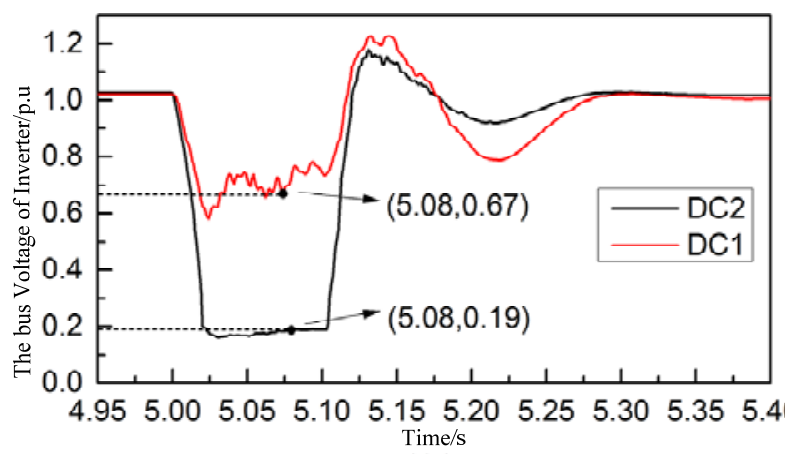

(a) Voltage drop

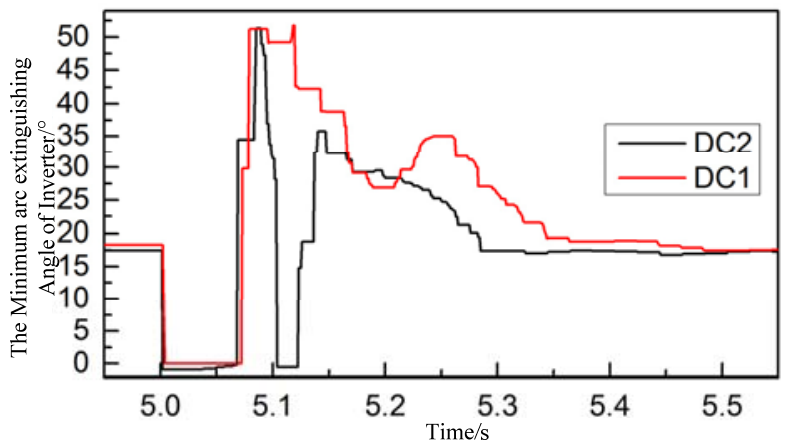

(c) The characteristics of extinction angle

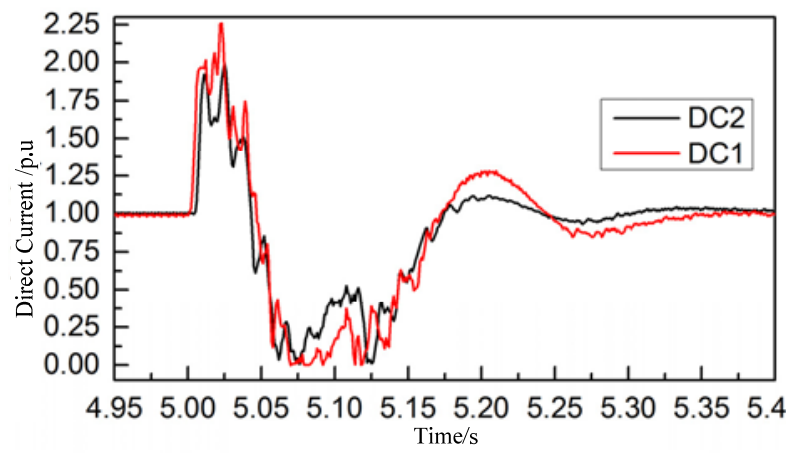

(b) The characteristics of current

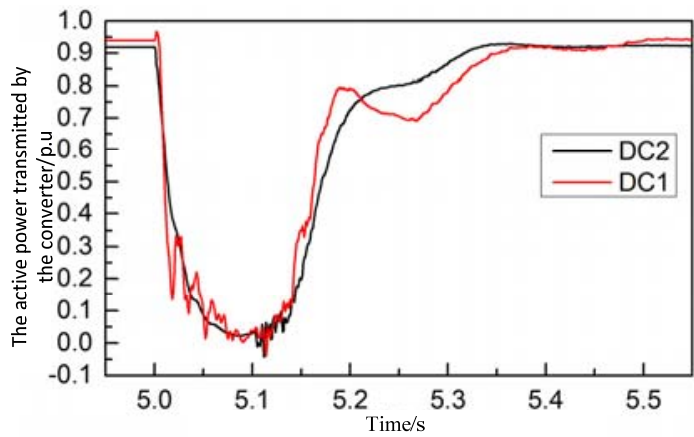

(d) The characteristics of converter transporting dynamic active power

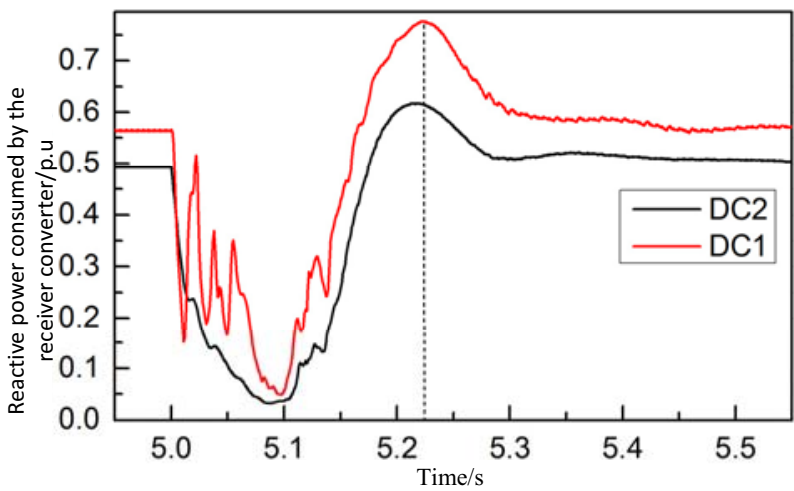

(e) The characteristics of converter consuming dynamic reactive power

Fig 4 The characteristics of DCs system without coordination

According to Fig. 3 and Equation, MIIF12 $\approx 0.30$ and MIIF21 $\approx 0.30$ can be deduced, is approximately equal to
Z12/Z11 and Z12/Z22 respectively, and the consistency of the two definitions is verified. 


\subsection{Analyze the Mechanism of the DC System After the Failure, Compare the influence of different recovery sequence on voltage recovery and power of converter station}

When a fault occurs on the DC2 converter bus, the voltage drops to 0.2 p.u. The simulation results of DC2 recovery are shown in Fig. 5.

In Fig. 4, the electric quantity adopts the unitary value. Known figure 4 (a) in DC2 converter bus fault during make voltage p.u fell to 0.1 , causing DC1 voltage drop to around $0.6 \mathrm{p} . \mathrm{u}$, at this time due to the constant power control inverter side, direct current appear larger overshoot (figure 4 (b)), the two dc inverter by the end of the arc Angle are dropped to zero (figure 4 (c)), After commutation failure occurred, the inverter side began to adjust to the control of constant arc extinguishing Angle. After $100 \mathrm{~ms}$, the fault was removed, the system began to recover at the same time, the voltage quickly recovered and overshot by about $0.2 \mathrm{p} . \mathrm{u}$, and the reactive power demand of the converter increased rapidly, resulting in subsequent commutation failure of DC2 DC. About $220 \mathrm{~ms}$ after the failure, both DC current and arc extinguishing Angle overshoot, and the overshoot of arc extinguishing Angle is very large (DC arc extinguishing Angle of DC1 and DC2 under normal operation is controlled to be about $18^{\circ}$, which reaches $38^{\circ}$ at this time). Reactive power consumption of converter almost reaches the peak at the same time (as can be seen from Fig. 4 (e)), and dynamic reactive power consumption of the whole system reaches the peak. As a result, the voltage and power oscillate greatly, and it takes about $400 \mathrm{~ms}$ for the power to be restored to stability (see Fig. 4 (d)).

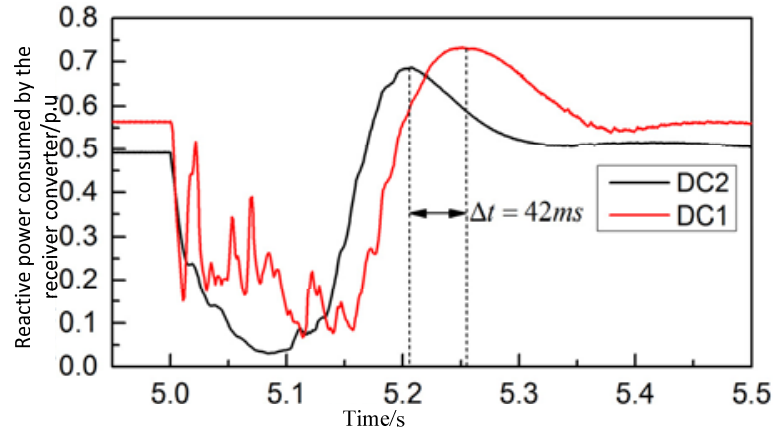

Fig 5. The characteristics of converter consuming dynamic reactive power when DC2 has the priority recovery

Based on the above analysis, the electrical characteristics during the fault are complex and difficult to determine. However, after the fault is removed, the unstable recovery will cause great impact on the system, such as the occurrence of subsequent commutation failure and the excessively high dynamic reactive power peak of the system, which will seriously damage the converter. Therefore, the coordinated recovery strategy of DC1 and DC2 should be adopted to ensure orderly recovery of each return DC. On the one hand, the occurrence of subsequent commutation failure should be prevented, and on the other hand, the dynamic reactive power consumed by the converter should be avoided to reach the peak at the same time during the recovery.

In the doubly-fed AC/DC system, the PI link controlled by the DC valve layer is shown in Figure 2. The control parameters of the PI link are adjusted and optimized to generate orderly recovery of each return DC. The peak time of reactive power consumed by the converter at the two dc receivers and the subsequent commutation failure are taken as the factors to measure the stability of the system, and the time required for dc to return to the steady state value is used to evaluate the speed of power recovery.

The sequence of DC recovery can be changed by changing the control parameters of PI link. The statistical data are shown in Table 1.

Tab 1. The statistics of different recovery Strategy

\begin{tabular}{|c|c|c|c|c|c|c|c|}
\hline \multirow{2}{*}{ fault node } & \multirow{2}{*}{$\begin{array}{l}\text { restore } \\
\text { order }\end{array}$} & \multirow{2}{*}{ DC name } & \multicolumn{2}{|c|}{ PI link parameters } & \multirow{2}{*}{$\begin{array}{l}\text { commutation } \\
\text { failure? }\end{array}$} & \multirow{2}{*}{$\begin{array}{c}\text { peak time Reactive } \\
\text { Power } \\
\text { consumption }(\mathrm{ms})\end{array}$} & \multirow{2}{*}{$\begin{array}{l}\text { time Active } \\
\text { Power restored } \\
\text { to Rated (ms) }\end{array}$} \\
\hline & & & $K_{p}$ & $T_{n}$ & & & \\
\hline \multirow{6}{*}{$\begin{array}{c}\mathrm{DC} 1 \\
\mathrm{AC} \\
\text { fault }\end{array}$} & \multirow{2}{*}{$\begin{array}{l}\text { at the same } \\
\text { time }\end{array}$} & DC1 & 0.40 & 0.015 & $\mathrm{~N}$ & 229 & 551 \\
\hline & & DC2 & 1.0 & 0.015 & $\mathrm{~N}$ & 217 & 341 \\
\hline & \multirow{2}{*}{ DC1 first } & DC1 & 0.50 & 0.010 & $\mathrm{~N}$ & 217 & $800+$ \\
\hline & & $\mathrm{DC} 2$ & 0.49 & 0.05 & $\mathrm{~N}$ & 243 & 551 \\
\hline & \multirow{2}{*}{ DC2 first } & DC1 & 0.30 & 0.045 & $\mathrm{~N}$ & 253 & 482 \\
\hline & & $\mathrm{DC} 2$ & 0.97 & 0.010 & $\mathrm{~N}$ & 203 & 376 \\
\hline \multirow{6}{*}{$\begin{array}{c}\mathrm{DC} 2 \\
\mathrm{AC} \\
\text { fault }\end{array}$} & \multirow{2}{*}{$\begin{array}{l}\text { at the same } \\
\text { tiem }\end{array}$} & DC1 & 0.40 & 0.015 & $\mathrm{~N}$ & 224 & 636 \\
\hline & & DC2 & 1.0 & 0.015 & $\mathrm{Y}$ & 217 & 335 \\
\hline & \multirow{2}{*}{ DC1 first } & DC1 & 0.5 & 0.010 & $\mathrm{~N}$ & 214 & 653 \\
\hline & & $\mathrm{DC} 2$ & 0.49 & 0.050 & $\mathrm{~N}$ & 250 & 551 \\
\hline & \multirow{2}{*}{ DC2 first } & DC1 & 0.30 & 0.045 & $\mathrm{~N}$ & 251 & 593 \\
\hline & & $\mathrm{DC} 2$ & 0.97 & 0.010 & $\mathrm{~N}$ & 209 & 382 \\
\hline
\end{tabular}

1) After the fault, if the DC system is restored at the same time, it is easy to cause the dynamic reactive power consumed by the end converter to reach the peak value of about $220 \mathrm{~ms}$ at the same time. At this moment, the system has a large reactive power demand, and the 
subsequent commutation failure may occur, which will bring a large impact on the $\mathrm{AC}$ voltage and voltage distortion, and at the same time seriously affect the service life of the converter. If the recovery is orderly, the peak value can be avoided at the same time, and the subsequent commutation failure can be avoided, and the purpose of protecting the converter can be achieved at the same time.

2) After the failure, if $\mathrm{DC1}$ (weak system) recovers first, the system power recovers to stability for the longest time, and even the severe shock of bus voltage and power at the receiving end commutator occurs, resulting in voltage distortion and voltage and power Angle instability, resulting in greater stability hidden danger to the system; If DC2 (strong system) is restored first, its restored voltage supports the system, so that the system can be restored to stability at the earliest, with robustness.

\section{Conclusion}

1) The MIESCR proposed by Cigre experimentally is strictly consistent with the MIESCR defined by Paulo et al. from the grid structure, which verifies that MIESCR has a clear physical meaning from the engineering and theory.

2) According to the size of MIESCR, the strong AC system is restored first, which plays the role of voltage and Angle support for the whole system, improves the AC voltage distortion rate, and avoids subsequent commutation failure.

3) If the DC subsystem is restored at the same time, the reactive power consumed by the converter will reach the peak at the same time, resulting in a large number of reactive power deficiency in the system. However, the MIESCR orderly recovery strategy can stagger the time when the reactive power peak of each converter occurs and improve the voltage stability of the system

4) when conventional recovery, the time required for the active power transmission of the converter to restore to the rated power is long, requiring $500 \sim 700 \mathrm{~ms}$. The MIDC system based on the MIESCR can restore the MIDC system to stability about $30 \mathrm{~ms}$ in advance.Centering on the application of multi-rotor UAV inspection system in safety and quality management of power gird projects, this paper elaborates on the composition of multi-rotor UAV system and flight control system, and establishes an evaluation scheme of UAV inspection based on the actual situation of power grid infrastructure projects. At last, according to the practical application effect, the efficiency of UAV inspection is measured from the aspects of inspection time, cost and safety risk. Practice has proved that UAV inspection plays a significant role in expanding the scope of control, improving work efficiency, reducing labor intensity and other aspects, and has a broad application prospect.

\section{References}

1. LIPS H P. Aspects of multiple infeed of HVDC inverter station into a common AC system. IEEE Trans on Power Apparatus and Systems[M], 1973, 92(2): 135-141.

2. REEVE J, LANE-SMITH S P. Muiti-infeed HVDC Transient Response and Recovery Strategies [J]. IEEE Transaction on Power Delivery, 1993, 8(4): 1995-2001.

3. DENIS L, ANDERSSON G. Power Stability Analysis of Multi-infeed HVDC Systems [J]. IEEE Transactions on Power Delivery, 1998, 13(3): 923931.

4. DENIS L, ANDERSSON G.. Voltage Stability Analysis of Multi-infeed HVDC Systems [J]. IEEE Transactions on Power Delivery, 1997, 12(3): 13091318.

5. LIN Weifang, TANG Yong, BU Guangquan. Study on Voltage Stability of Multi-infeed HVDC Power Transmission System [J]. Power System Technology, 2008, 32(11): 7-12.

6. WANG Juanjuan, ZHANG Yao, XIA Chengjun, et al. Survey of Studies on Transient Voltage Stability of AC/DC Power System [J]. Power System Technology, 2008, 32(12): 30-34.

7. SHAO Yao, TANG Yong. Current Situation of Research on Multi-infeed AC/DC Power Systems [J]. Power System Technology, 2009, 33(17): 24-30.

8. CIGRE Working Group B4.41. Systems with Multiple DC Infeed [R]. CIGRE, 2008.

9. Paulo Fischer de Toledo, Bernt Bergdahl, Gunnar Asplund. Multiple Infeed Short Circuit Ratio-aspects Related to Multiple HVDC into One AC Network [J].IEEE/PES Transmission and Distribution Conference \& Exhibition. Dalian, China, 2005. 